\title{
Modernismo, historiografia e sociabilidade intelectual: apontamentos sobre o quinto volume da coleção Biblioteca Histórica Brasileira (1931-1940) \\ Modernism, historiography and intellectual sociability: notes on the fifth volume of the
}

Brazilian Historical Library Collection (1931-1940)

\section{Rafael Pereira da SILVA*}

Resumo: Este artigo tem como pano de fundo pensar a trajetória do livro Memórias de um colono no Brasil, do imigrante suíço Thomas Davatz, o quinto volume publicado pela Coleção Biblioteca Histórica Brasileira, com base nas discussões do campo da História Intelectual. Para tanto, o texto é dividido em duas partes. Primeiro, levo em conta a circulação do livro entre os modernistas paulistas e sua repercussão na imprensa a partir dos artigos publicados no Diário Nacional em 1931. Em seguida analiso um pequeno conjunto de cartas recebidas por Sérgio Buarque de Holanda, em que é possível perceber as dificuldades enfrentadas na tradução e publicação da obra, anos depois, pela Coleção. Nas cartas, verificam-se ainda indícios da construção de um projeto de história nacional que em muito se assemelhava à do Instituto Histórico e Geográfico Brasileiro (IHGB).

Palavras-chave: modernismo; historiografia; cartas; sociabilidade.

Abstract: This article is in the background thinking the trajectory of the book Memórias de um colono no Brasil the Swiss immigrant Thomas Davatz, the fifth volume published by the Brazilian Historical Library Collection, based on the discussions of the field of Intellectual History. To this end, the text is divided into parts. First, take into account the circulation of the book between the modernists and its repercussion in the press through articles published in Diário Nacional in 1931. Then I analyze a small set of letters received by Sérgio Buarque de Holanda where you can see the difficulties in the translation and publication of the work year after the collection. In the letters there is still evidence of the construction of a national history project that greatly resembled that of the Historical and Geographic Brazilian Institute (IHGB).

Keywords: modernism; historiography; letters; sociability.

\footnotetext{
* Mestre em História- Doutorando- Programa de Pós-Graduação em História- Instituto de Filosofia e Ciências Humanas- UNICAMP- Universidade Estadual de Campinas, Rua Cora Coralina, s/n, Cep 13083-896, Campinas, São Paulo- Brasil. Bolsista CNPq. E-mail: rapersilva@gmail.com
} 


\section{Apresentação}

No final da década de 1930, um conjunto de esforços realizados por intelectuais modernistas deu início a uma série de publicações de textos raros que tinham, entre outras, a característica de documentar o Brasil, contribuindo, dessa forma, para os debates sobre a identidade nacional. Nesse contexto surgiu a Biblioteca Histórica Brasileira. O diretor da coleção foi o bibliófilo Rubens Borba de Moraes.

A Biblioteca contaria com uma cuidadosa e rigorosa seleção de títulos "lindamente impressos", em traduções fiéis e integrais, revistas e devidamente anotadas por especialistas. Seu custo para o leitor comum seria de $20 \$ 000$ a 30\$000. Para os mais exigentes ou colecionadores, as edições de luxo custariam 100\$000. Devido à dificuldade e ao alto custo das impressões coloridas, as imagens sairiam publicadas em cor única. A Coleção adquiriu tamanha importância que, além dos cerca de sete mil exemplares vendidos no primeiro ano, teve seu índice completo publicado na Revista do Instituto Nacional do Livro. Suas publicações encerraram-se em fins dos anos 60, para mais tarde serem reeditadas nos anos 80, pela editora Itatiaia de Belo Horizonte (HALLEWELL, 2005, p. 502).

Nesse contexto, o empenho e a amizade de intelectuais renomados, como Sérgio Milliet - tradutor de Rugendas, cuja obra Viagem Pitoresca ao Brasil serviu como primeiro volume da Coleção -, Affonso Arinos de Mello Franco, Sérgio Buarque de Holanda, José Honório Rodrigues, dentre outros, foram fundamentais para que se tirasse do papel um projeto editorial e historiográfico que, além da tradução de relatos e memórias de viajantes, seria complementado com a localização de documentos inéditos referentes ao País. Nesse quadro, é importante ressaltar ainda que, mesmo que estivesse protegida pelo rótulo do modernismo, a proposta da Coleção não deixava de apresentar certas semelhanças com o que fora feito pelos historiadores da geração anterior, muitos deles ligados ao IHGB, fundado um século antes.

É o que aponta Fábio Franzini ao estudar outra coleção do mesmo período, a Documentos Brasileiros, da editora José Olympio. Ao problematizar a ausência de textos marxistas entre suas publicações, o autor afirma que o mesmo não ocorria com uma história de corte mais tradicional no sentido de permanência e predominância, em algumas abordagens, de certos traços característicos da produção historiográfica oitocentista, como o foco em personagens e acontecimentos políticos, a sobreposição aparentemente acrítica de 
nomes, fatos e datas. Por outro lado, tomadas em conjunto elas espelhariam a continuidade da história événementielle, mas agora preocupada e atenta ao revisionismo do passado estabelecido, algo que a levava mesmo a se abrir a novas questões e a novos temas de nossa história (FRANZINI, 2006, p. 185).

O quinto volume foi Memórias de um colono no Brasil, do imigrante suíço Thomas Davatzi . O livro - raro, na avaliação de Rubens Borba de Moraes - era pouco conhecido entre os estudiosos e intelectuais da época. Foi o amigo Yan de Almeida Prado quem o fez circular entre um restrito grupo de intelectuais, já que possuía "o único exemplar conhecido no Brasil e teve a generosidade de permitir que dele nos utilizássemos para esta edição" (MORAES, 1941, p. 3). Nesse sentido, é importante ressaltar como a obra ecoou entre o pequeno grupo. Lido também por Mário de Andrade, suas denúncias repercutiram na imprensa paulista mediante duas crônicas publicadas no Diário Nacional no ano de 1931, nas quais é possível perceber de que maneira o texto foi "digerido" pelo modernista.

Os apontamentos que busco esboçar neste artigo resultaram da leitura destas Memórias. Nos campos minados da teoria da recepção, da história do livro e de um diálogo próximo à crítica literária, seria viável explorar temas como o trabalho de tradução feito por Sérgio Buarque de Holanda, as relações entre autoria e narrativa constituídas por Davatz, ou ainda a imagem por ele construída em suas memórias, de um tipo ideal de leitor. Entretanto, o caminho percorrido foi outro. O recuo no tempo possibilitou acompanhar alguns momentos que anteciparam a publicação de Memórias de um colono no Brasil, numa espécie de antecena, de onde se observou a complexidade da organização de um texto literário. Este é o objetivo central.

A abordagem aqui proposta se insere em um debate atual dentro dos domínios da história cultural. Sendo assim, podemos nos perguntar: qual seria a melhor maneira, dentro desse domínio, de pensar uma história dos intelectuais e a partir de quais abordagens deveríamos cercar nosso objeto? Longe de uma resposta exata, algumas considerações tornam-se providenciais, tendo em vista as celeumas historiográficas das últimas décadas.

Mais do que uma categoria fechada no quadro historiográfico, a História intelectual ou a História dos Intelectuais, como a designa a historiografia francesa - constitui um campo de possibilidades ainda em discussão situada nos limites das histórias política, social e cultural. Deste modo, não existe um consenso entre os estudiosos sobre como defini-la. Em meados dos anos 1980, em particular na Europa, a percepção sobre o papel dos intelectuais 
mudou de direção e possibilitou uma inovação na historiografia destes, quando, de tradicionais juízes de seu próprio engajamento, passaram a ser considerados um objeto histórico similar a outros, passíveis de serem investigados pelos especialistas das ciências humanas.

Para Jean-François Sirinelli, a história intelectual ou dos intelectuais pode ser vista sob duas perspectivas entrelaçadas, ambas presentes na famosa petição J'accuse!, publicada em 1898 no diário L'Aurore littèraire, artistique, sociale, por Émile Zola, em defesa do capitão Alfred Dreyfus: a) uma, ampla e social, referente à atividade profissional, que englobava os criadores e os mediadores culturais; b) e outra, mais estreita, fundada na noção de engajamento.

Dentro dessas possibilidades, a história dos intelectuais possibilita a exegese de textos, impressos e manuscritos - entendidos como objetos fronteiriços, que estão no horizonte de diferentes interesses e disciplinas, como a história política, a história das ideias, a história das elites e a história da literatura -, em cuja gênese, circulação e transmissão os intelectuais desempenham um papel decisivo. Por outro lado, a sua história social exige a análise sistemática de elementos dispersos, conectados com a realidade da história efetiva do mundo contemporâneo, podendo assim reconstruir redes de sociabilidade.

Para este artigo, as redes são entendidas como uma "ferramenta" explicativa para compreender a organização e a dinâmica do campo intelectual, com suas amizades e inimizades, vínculos e tomadas de posição. Assim, o estudo das trocas epistolares e dos circuitos editoriais constitui este artigo, como exemplo concreto para a análise dessas redes, às quais podemos ainda articular, se for o caso, conceitos como circulação, apropriação e recepção da obra literária ou artística, reelaboração ideológica e de geração, para compreender as filiações, as rupturas e as tramas que se passaram neste "pequeno mundo".

A História Intelectual também se pode ater à análise das ideias políticas ou se ampliar a um diálogo mais próximo no campo da história cultural. No primeiro caso, por exemplo, J.G.A. Pocock preocupa-se com o contexto de elaboração dos vocabulários políticos, ou seja, trata-se de situar os textos no seu campo específico de ação ou de atividade intelectual, levando-se em consideração quem os maneja e com quais objetivos. $\mathrm{O}$ autor estabelece uma divisão da linguagem política em dois níveis: língua (langue) e fala (parole), com o objetivo de compreender como ambas interagem ao longo do tempo. Assim, por meio dos atos de fala 
(speech acts) o sujeito se apropria da língua, seja para reafirmá-la ou inová-la mediante a reelaboração dos conceitos do discurso.

No segundo, Roger Chartier concebe a história intelectual como sinônimo de história cultural. Propõe um programa crítico, tanto da oposição entre a alta cultura e a cultura popular - que estariam unidas por fenômenos de circulação e de apropriação - quanto entre criação e consumo, produção e recepção, sustentando que o sentido da obra também é constituído por meio das suas interpretações. Em suma, o historiador deve investigar a produção intelectual na sua relação com as outras produções culturais que lhes são contemporâneas e, ao mesmo tempo, nas suas relações com os referentes situados em outras esferas da totalidade social (socioeconômica ou política).

De modo geral, as pesquisas recentes no campo da História Intelectual vislumbram certas inovações nas análises, em que aparece um tratamento explícito ao estilo ou a exploração e valores meta-históricos, se pensarmos nas polêmicas levantadas por Hayden White, que configuram os textos, ou a busca de linguagens, no sentido de Pocock, historicamente construídas e transmitidas de texto a texto ao longo de extensos períodos históricos. Por fim, as análises feitas com base nas fontes epistolares, dos periódicos culturais, das biografias intelectuais ou dos arquivos privados são portas de entrada bastante relevantes nesse campo ${ }^{\text {ii }}$.

A partir das impressões de leitura publicadas na imprensa por Mário de Andrade, bem como de uma pequena sequência de cartas envidas a Sérgio Buarque entre 1939 e 1940, foi possível perceber minúsculos fragmentos das imensas dificuldades e esforços despendidos por esses intelectuais na concretização de um projeto editorial.

\section{Agora, é não desanimar! (...) Mário de Andrade encontra Davatz}

O escritor estreou no Diário Nacional em 20 de agosto de 1927 com a crítica Brecheret. No jornal, o autor exerceu a função de crítico de artes plásticas, música e literatura. Após uma viagem ao Nordeste em 1928 torna-se cronista. Mário de Andrade publicou seus textos até 25 de setembro de 1932, quando o jornal foi fechado. Telê Ancona Lopez afirma que suas crônicas no jornal constituíram um importante veículo de seu ideário e, não raro, 
suscitaram controvérsias e debates que, de certa forma, lograram criar um público leitor (LOPEZ, 1976, p. 21).

Lopez enfatiza ainda que o reconhecimento das contribuições que as crônicas de Mário de Andrade ofereceram para a consolidação das propostas modernistas na imprensa de massa e os subsídios que trouxeram para o estudo do ideário nacional do escritor lhe impuseram o desafio de organizar uma edição de caráter documental, capaz de conduzir aos dias de hoje a totalidade da produção do autor nesse veículo (Idem).

Ao levantar a ideia de uma "consolidação da proposta modernista na imprensa de massa”, da qual Mário de Andrade seria o grande expoente, Lopez reforça a ideia de um modernismo homogêneo, com bases fincadas em São Paulo e que teria a Semana de 1922 como grande marco inaugural de um projeto que previa, entre outras coisas, diagnosticar a fundo a identidade nacional. Daí, um paradoxo: o Brasil deveria ser visto por dentro, incluindo-se aqui a busca pela originalidade de certos hábitos culturais, pelo exótico, pelo regional, porém deveria também ser explicado pelo polo irradiador do modernismo - a cidade de São Paulo, moderna e urbana.

Para Monica Velloso, foi a própria história literária que ajudou a divulgar tais ideias. Criou-se uma memória em que a Semana de 22 se estabeleceu como um divisor de águas, e tudo o que aconteceu de moderno no Brasil nas primeiras décadas do século XX passou a ser considerado uma espécie de premonição dos temas de 22 (VELLOSO, 2010, p. 22).

Ponto importante na crítica da autora é o fato de que o registro canônico agregou em um único bloco homogêneo distintas sensibilidades e diferenciações literárias e artísticas, dentre as quais, os parnasianos, os decadentistas, os simbolistas e os regionalistas. Tal procedimento facilitou $\mathrm{o}$ ato do reconhecimento, pois esses grupos distintos foram identificados como "antecessores" do modernismo. Ou seja, perderam-se as especificidades de cada grupo e as diferentes articulações que pudessem vir a estabelecer com o moderno (Idem, p. 22-23).

Nesse sentido, a narrativa hegemônica do Modernismo foi uma construção empreendida pelas vanguardas paulistas, que a atualizaram ao longo das décadas de 1930, 40 e 50. Heloísa Pontes demonstra que "toda a história intelectual e cultural paulista é caudatária de suas interpretações e da posição privilegiada que seus atualizadores ocuparam no sistema local de produção cultural". Sistema que englobava uma ampla e sofisticada rede de instituições que incluía, por exemplo, a Faculdade de Filosofia e Letras da USP (local de 
formação e de trabalho de Telê Ancona Lopez e do canônico Antonio Cândido), os jornais Folha de São Paulo e O Estado de São Paulo, as revistas Anhembi e Clima, além das editoras Nacional e Martins (PONTES, 1998, p. 36).

Algumas décadas mais tarde, a memória historiográfica constituída sob o mito fundador da Semana de 22 passou a ser objeto de problematização na área dos estudos históricos. Para Velloso, a partir dos anos 80 o fenômeno da circulação de ideias e a capacidade crítico-inventiva dos diversos agentes sociais na construção das representações e práticas foram aspectos fundamentais para se proceder à reconfiguração do social. "A sociedade brasileira passou a ser pensada a partir de uma reconceituação da temporalidade histórica, em decorrência da qual foram reformuladas as categorias do moderno e da tradição" (VELLOSO, op.cit., p. 25).

Para a autora, muitos desses trabalhos apresentaram uma contribuição inovadora: a necessidade de reavaliar o conceito de tradição e as articulações concretas no conjunto da vida cultural brasileira. Entender a dinâmica da tradição, os conceitos de continuidade e a ruptura, revendo a questão da importação de ideias, foi tema que mobilizou intensamente o debate intelectual desse período (idem).

Velloso lembra ainda que estudiosos como Luis Costa Lima, Alfredo Bosi e Silviano Santiago foram fundamentais no processo de releitura do modernismo brasileiro. Enfatizando a diversidade da cultura brasileira, esses autores contribuíram para o entendimento da temporalidade múltipla que marcava a brasilidade. Ao longo dos anos 80 , foi importante rever criticamente as ideias que reforçavam uma visão do modernismo baseada na estética da ruptura (ibidem, p. 26).

Não mais se deveria falar de Modernismo, que, a partir das críticas, ampliava seus significados para além do eixo Rio-São Paulo. Em meio ao processo de reconceituação, o termo deixa de ser identificado como momento-ruptura na vida sociocultural brasileira. Surgia agora como resultante de um processo histórico em que se mesclavam as mais distintas tradições, espaços, temporalidades, atores e configurações. Crítico de uma ideia homogênea de modernismo, portanto adepto da pluralidade do termo, o historiador alemão Peter Gay não se admirava de que os comentaristas, os entusiastas e os comerciantes mais venais da indústria cultural costumassem mistificar as tentativas de uma avaliação geral do modernismo. Para ele: 


\begin{abstract}
A mesma vagueza cerca o rótulo pespegado a obras artísticas e literárias: na verdade, desde a metade do século XIX utilizou-se o termo 'modernismo' para todo e qualquer tipo de inovação, todo e qualquer objeto que mostrasse alguma dose de originalidade. Assim, não surpreende que os historiadores culturais, intimidados com o programa caótico e sempre variável a que tentam dar uma ordem retrospectiva, tenham recorrido à prudência do plural: 'modernismos' (GAY, 2009, p. 17).
\end{abstract}

Nessa passagem, a ideia da pluralidade pode ser explicada também pela metáfora familiar, pela qual podemos imaginar uma grande família muito interessante e variada, com todas as suas expressões individuais diferentes, mas unidas por alguns laços fundamentais, como necessariamente são as famílias. Tais laços são o que Peter Gay chamou de estilo modernista, em suma, "um clima de ideias, sentimentos e opiniões" (Idem, p. 18-19). Por essa perspectiva, por exemplo, é possível pensar o Modernismo brasileiro como o desencadeamento de vários movimentos que, ocorrendo em diferentes temporalidades e espaços, alcançaram de forma distinta grande parte do País (VELLOSO, op.cit., p. 29).

Campo fecundo de observação dos diferentes modernismos, o exemplo do Ministério da Educação e Saúde Pública (MES), encabeçado por Gustavo Capanema, se torna emblemático nesse sentido. Ao contrapor a tese de Sérgio Miceli de que houve cooptação dos intelectuais por parte do Estado durante o regime Vargas, Maria de Fátima Piazza aponta que:

\footnotetext{
Sob a égide do mecenato Capanema foi que o dilema da participação dos intelectuais e artistas na política teve seu ponto nevrálgico. Aqui vislumbrase o encontro de uma geração de intelectuais e artistas modernos, oriundos de diversos estados da federação, cujo destino foi uma repartição pública, o Ministério da Educação e Saúde Pública (MES). Foi desse órgão da administração pública federal , conduzido por dois mineiros, o ministro Capanema e seu chefe de gabinete, o poeta e escritor Carlos Drummond de Andrade, que surgiu a "constelação Capanema (PIAZZA, 2003, p. 24).
}

A "constelação" nada tinha a ver com a censura imposta pelo Departamento de Imprensa e Propaganda (DIP), muito menos com a repressão e violência impostas por outros aparelhos do estado varguista. Gozava, antes, de certa autonomia e liberdade para que seus projetos pudessem ser colocados em prática. No MES, transformaram o "fardo-burocrático" em instituições que revelaram o Brasil moderno - como o Serviço do Patrimônio Histórico e Artístico Nacional (hoje, IPHAN), o Instituto Nacional do Livro, o Serviço de Radiodifusão Educativa, o Serviço Nacional de Teatro, entre outros (idem, p. 29). 
A autora também aponta que na formulação de um pensamento moderno no Brasil cruzaram-se matrizes distintas do modernismo. Por exemplo, no diálogo entre o poeta Carlos Drummond de Andrade e o escritor Mário de Andrade houve diferenças no "olhar a realidade brasileira". O mineiro contemplava o Brasil com um "olhar de sociólogo", preocupado com o estabelecimento de grandes e universais linhas de interpretação do Brasil, capazes de abrir ao País a chave de comunicação com o mundo civilizado. Já o escritor paulista admirava o País com um "olhar de etnógrafo" e defendia pedagogicamente a interação dos diversos Brasis ao grande projeto de reconstrução nacional (ibidem, p. 28).

De volta ao Diário Nacional, o órgão de oposição ao Partido Republicano Paulista era diretamente ligado ao Partido Democrático e encabeçado por integrantes da Semana de 22. Quem respondia por sua gerência era Sérgio Milliet, sob o pseudônimo de Sérgio M. da Costa e Silva, além do redator-chefe, Antonio Carlos Couto de Barros. A direção, no início, ficou a cargo de Paulo Nogueira Filho. Em 1929, Paulo Duarte, membro do Partido Democrático, juntou-se ao grupo para assumir a direção do periódico, dois anos mais tarde (LOPEZ, op.cit., p. 16).

O matutino foi lançado oficialmente em 14 de julho de 1927 e atravessou momentos significativos da história nacional, como a Revolução de 30, na qual manifestou apoio e logo depois, oposição, e a Revolução Constitucionalista de 1932, ano em que deixou de circular após a derrota paulista ${ }^{\mathrm{iii}}$. O jornal nunca se valeu de uma situação financeira completamente satisfatória, mas suas páginas deram cobertura a acontecimentos importantes no campo da literatura, do teatro, das artes plásticas e da música. Além das publicações de Mário de Andrade, contou ainda com a colaboração de Manuel Bandeira, Lasar Segall, Prudente de Moraes, neto, entre outros.

Cerca de 770 textos - entre crônicas, artigos, ensaios, poemas e ficção - foram deixados pelo escritor nas seções Arte e Livros e Livros e Livrinhos do Diário Nacional (LOPEZ, op.cit., p. 16). Como já mencionado, foi pelas mãos de Yan de Almeida Prado que o livro de Thomas Davatz se tornou conhecido entre os modernistas, e delas Mário de Andrade o recebeu para lê-lo em alemão e sobre ele tecer dois artigos no Diário Nacional.

O primeiro, publicado em 9 de agosto de 1931, expunha o conteúdo geral da obra, considerando o livro "uma das informações mais interessantes sobre a colonização teuto-suíça tentada pelo senador Vergueiro". Em relação à composição, Andrade afirmava serem os dois primeiros capítulos bastante monótonos, os quais tratavam das condições gerais da província 
de São Paulo e das tentativas de colonização em substituição à mão de obra escrava. Por outro lado, "o que agrada um bocado é a íntima ingenuidade do narrador e o ar sincero de sua escrita, que por esses dois caracteres possivelmente se aproxima bem da verdade".

Andrade deleitou-se com o tom de espanto do emigrante frente aos desmandos e abusos sofridos pelos colonos e que descrevia as condições de vida dos trabalhadores, a burla dos contratos, os engodos pelos quais passaram, bem como os mecanismos de opressão que transformavam os trabalhadores formalmente livres em escravos brancos, fruto do endividamento resultante da viagem para o Brasil e das cadernetas de compras vinculadas aos armazéns das fazendas, sempre mais caros.

Em outra passagem, mencionando o relato sobre a agitação dos colonos de Ibicaba, Andrade ressaltava a continuidade dos métodos da velha política senhorial, que permaneciam semelhantes mesmo com a nova onda de emigração europeia, e referenciava o ponto alto da obra:

$\mathrm{Na}$ descrição desse levante dos colonos contra seus opressores o livro se torna interessantíssimo: os processos mais perrepistas de opressão, de disfarce, de prepotência são utilizados contra os colonos e especialmente contra Davatz. Este é um 'revolucionário' ameaçado de morte com negrões assalariados esperando ele nas tocaias da noite; o pretexto dos colonos é desvirtuado como um novo Palmares perigosíssimo"iv (ANDRADE, 1976, p. 410).

Para Ilka Cohen, “ao reproduzir as acusações de Davatz, Mário de Andrade resgatava toda uma visão negativa do sistema de colonização instituído pelos fazendeiros paulistas no século XIX, contrariando a visão oficial de parcela da elite paulistana à qual se opunha politicamente" (COHEN, 2001, p. 186). Tanto a autora quanto Telê Ancona Lopez são enfáticas ao afirmar que os comentários de Mário de Andrade provocaram reações nos altos setores da sociedade, pois, na semana seguinte, o autor iniciava seu escrito com uma explicação irônica:

O interesse apenas de cronista, pelas anedotas que tinha a relatar, me fizeram esquecer que sem ressalva alguma de minha parte o relato iria ferir o sentimento daqueles que guardam com justiça a memória do velho paulista (...) está claro que com meu artigo de domingo passado não tive a mínima intenção de chocar o sentimento de ninguém. Nem mesmo de diminuir as benemerências do senador Vergueiro (...) quis foi dar conta de um livro que poucos conhecem, cujo valor é inegável para nós e cujas anedotas divertiam. 
Mas que a verdade dele seja incontestável, não posso afirmar (ANDRADE, op.cit., p. 413).

Para Lopez, os títulos dos textos publicados por Mário de Andrade são bastante significativos e reveladores de uma ironia própria do autor no trato do conteúdo do livro. No primeiro artigo cuidava da apresentação de uma obra rara do século XIX e, ao relembrar os episódios reescrevendo-os, deixava nas reticências do título de sua crônica uma referência velada à opressão que acreditava ainda existir em São Paulo.

No segundo, rebatia certas acusações: "Mário volta à carga, 'Agora é não desanimar!', reduzindo a pontuação final a uma única e irônica exclamação e trabalhando o texto com a alternância de fontes retiradas do próprio livro. Para tanto, escolheu três documentos, apresentados ao longo de seu artigo: uma carta do Dr. Hanser ao senador Vergueiro; uma declaração do mesmo senhor Hanser ao diretor da fazenda, o senhor Jonas; e, por último, uma carta dos próprios colonos ao senhor Luiz Vergueiro, filho do senador. Após exposição das fontes, Andrade encerrava a crônica com afirmações que defendiam a causa do fazendeiro, “cuja memória não tive a intenção de desprestigiar, mas desprestigiava sem esta documentação a favor dele" (LOPEZ, op.cit., p. 47).

Desse modo, o livro de Thomas Davatz constituía não apenas outra mera descrição do Brasil pitoresco, antes abordava temas delicados como a opressão, os desmandos dos poderosos, as reações dos oprimidos, as relações de trabalho nos sistemas de parceria nas fazendas de café, aspectos certamente pouco confortáveis e principalmente pouco conhecidos pelo público leitor nacional da época. Tal foi a repercussão do livro de Davatz que Andrade, pouco tempo depois, o incluiu entre as 20 obras que se deveriam ler para conhecer o Brasil (COHEN, op.cit., p. 187-188).

\section{Cartas para Sérgio: trocas epistolares na antecena de um projeto literário}

Prática comum no meio intelectual brasileiro da primeira metade do século $\mathrm{XX}$, as correspondências tornaram-se, na última década, objetos/fontes privilegiados de pesquisas nas mais diversas áreas, dentre as quais, a história e a crítica literária. Nesse sentido, cada vez mais comuns são as publicações de coletâneas de cartas que, junto com os diários, as 
biografias e autobiografias, ganham cada vez mais espaço nas vitrines das livrarias, movimentando o mercado editorial e, ao mesmo tempo, aguçando a curiosidade e a imaginação dos pesquisadores e dos leitores comuns.

Por não serem simples fontes de informação, as correspondências constituem um tipo específico de escrita própria, bem como os diários, as biografias, as autobiografias, os arquivos pessoais e as memórias. São registros produzidos no âmbito do privado que podem revelar vestígios de trajetórias de vida, de redes de sociabilidade intelectual e política, de personagens importantes ou de anônimos, e fornecer subsídios para uma história das práticas culturais, que na última década do século $\mathrm{XX}$ passou a reconhecer novos objetos, fontes, metodologias e critérios de verdade histórica (GOMES, 2004, p. 13-14).

Assim, as cartas enviadas por Rubens Borba de Moraes a Sérgio Buarque de Holanda podem-se somar à discussão de aspectos já conhecidos de suas vidas e da movimentação dos bastidores da publicação de uma obra. Nesse aspecto, o empenho na divulgação de um projeto estético, as divergências entre grupos e os comentários sobre a produção literária e artística contemporâneas aos diálogos contribuem para que se possa compreender que a cena literária (livros, revistas, jornais, etc.) tem raízes profundas nas antecenas, em que se situam as linhas de força do movimento, percebidas, entre outras fontes, no vaivém das cartas (MORAES, 2009).

No que envolve a criação de uma cultura epistolar, Teresa Malatian aponta o XIX como o século das correspondências. Para a autora, o hábito epistolar difundiu-se por diversas camadas sociais, tanto na Europa como na América, e a escrita de cartas - que podiam ser de amizade, de amor, familiares, pedidos, recomendações, trabalho, conselhos, censura, queixas, louvor, agradecimentos, etc. - buscava satisfazer o ímpeto de intimidade e privacidade que acompanhava o estabelecimento da ordem burguesa no Ocidente (MALATIAN, 2009).

Reveladoras, sobretudo, de fragmentos da vida íntima dos interlocutores, de momentos perdidos no tempo após a sua composição, as cartas sempre suscitaram, em seus autores ou destinatários, sentimentos ambivalentes de desejo de preservação ou de destruição. Desse modo, o desejo de salvar vestígios de vidas, de laços estabelecidos, de afetos experimentados permitiu que elas sobrevivessem silenciosas em arquivos pessoais, muitos deles hoje abertos ao público (idem).

Se por um lado as fontes epistolares demonstram-se verdadeiros "tesouros" ao gosto dos pesquisadores, por outro uma análise mais acurada desse tipo de documento impõe, em geral, 
certos cuidados de rigor metodológico, em especial quando personagens ilustres, intelectuais, políticos, celebridades passam a ser o foco da devassa e o objeto de debates promovidos por jornalistas, historiadores, ensaístas, literatos e curiosos, dentro ou fora do espaço acadêmico.

Nesse sentido, Teresa Malatian chama especial atenção para o fato de que:

A dificuldade é proporcional à relevância social, política ou cultural do correspondente em pauta, pois, no caso de figuras públicas, torna-se mais difícil o trato com a quantidade e a dispersão dos conjuntos documentais a serem reunidos, além de ocorrer um confronto com a imagem do indivíduo já construída e consolidada pela memória e pela História (ibidem, p. 203).

No que foi exposto, é importante ressaltar a fragmentação desse tipo de fonte/objeto. Não raro, as cartas inserem-se nos arquivos como séries documentais dispersas, pois, quando chegam ao pesquisador, tanto podem ter sofrido uma seleção prévia por parte da família ou donatários que têm por interesse a conservação de uma memória oficial do correspondente ou terem sofrido restrições por parte do próprio autor que, por motivos variados, não guardava as cópias das cartas que enviava tampouco todas as que recebia. Por esses motivos, muitos diálogos epistolares sofrem espaçamentos temporais ou tornam-se unilaterais. Assim, cabe ao historiador tentar complementá-los com outras fontes.

Em meio às discussões sobre a identidade nacional que vigoravam nos anos 30, surgiram algumas coleções propícias a trazer à tona temas históricos. A Coleção Azul, editada por Afonso Schmidt, refletia, por exemplo, o calor do debate político ao discutir temas como o tenentismo, a organização nacional, os rumos para o futuro do Brasil. Já a Brasiliana, publicada pela Companhia Editora Nacional iniciada em 1931, nasceu com a intenção de reverenciar grandes figuras do passado e foi encarada como uma das primeiras manifestações do novo interesse pelo Brasil e por sua herança (COHEN, op.cit., p. 183). Das coleções da época, talvez a mais conhecida fosse a Documentos Brasileiros da Livraria José Olympio Editora, cujo texto inaugural em 1936 foi Raízes do Brasil, de Sérgio Buarque de Holanda. No prefácio da obra, Gilberto Freyre enfatizava que a coleção e seu editor estavam sintonizados com as discussões do período e afirmava que "ao interesse pela divulgação do romance brasileiro elle [o editor] junta agora o interesse pela divulgação do documento virgem e do estudo documentado que fixe, interprete ou esclareça aspectos significativos da nossa formação ou da nossa actualidade" (FREYRE, 1936, p. V). 
Publicado pela Livraria Martins Editora em 1941, Memórias de um colono no Brasil fazia parte da coleção Biblioteca Histórica Brasileira, dirigida por Rubens Borba de Moraes. Quanto aos objetivos da coleção, Sérgio Milliet refere-se a eles na introdução ao quarto volume dedicado ao pintor e desenhista francês Jean-Baptiste Debret ${ }^{\mathrm{v}}$ :

\begin{abstract}
A escrita de um Rugendas ou de um Debret assemelha-se antes à de um chefe de seção, em seus pobres relatórios, que à de um literato habituado ao valor das palavras e aos segredos da sintaxe. (...) Bem sei que se pode perguntar: por que então traduzir essas obras? Evidentemente do ponto de vista literário não haveria motivo algum para fazê-lo. Mas nem só de literatura vive o homem; ao contrário, cada vez menos vive dela. E cada vez mais de documentos, de dados objetivos, úteis à solução de seus problemas hodiernos (MILLIET, apud, COHEN, op.cit., p. 183).
\end{abstract}

Os apontamentos de Milliet evidenciam a preocupação de publicar na coleção os registros produzidos pelos viajantes europeus, levando-se em conta muito mais o espírito documental das obras do que o seu valor literário. Nesse aspecto é importante perceber as semelhanças entre o projeto de publicação de documentos proposto pela Biblioteca e o intento realizado pelos historiadores do Instituto Histórico e Geográfico Brasileiro (IHGB) no século XIX. Ambos estavam inseridos numa discussão identitária e cada qual a seu tempo, com os postulados próprios de uma história comprometida com o desvendamento do processo de gênese da nação (GUIMARÃES, 1988, p. 6), como bem demonstra Monica Velloso:

Na genealogia do moderno brasileiro os autores recorrem a interpretações
que priorizavam novas lógicas civilizacionais ainda sem tradições definidas.
A vivência limiar entre o universo da ordem e da desordem, do legal e do
marginal e a superposição do privado e do público, fenômenos
particularmente acentuados na capital federal, podem tê-los sensibilizado a
historicizar modos de ser do nacional (VELLOSO, op.cit., p. 87 ).

As características aqui destacadas para o movimento modernista revelam uma espécie de lugar-comum entre o pensamento histórico do século XIX, ligado ao IHGB, e o das primeiras décadas do século XX. Fosse sob o manto imperial ou sob a égide da República, a busca pela identidade nacional deveria passar necessariamente pela escrita da história. Nesse movimento que expõe o curso da disciplina no Brasil, um tema em especial assume total centralidade: a construção da metáfora do parentesco para caracterizar as relações entre o Brasil e a antiga metrópole (GUIMARÃES, op.cit., p. 7) ${ }^{\mathrm{vi}}$. Desse modo se constituiu uma narrativa em que os primeiros contatos entre europeus e indígenas serviriam de mito de 
origem para diversas interpretações, ou seja, a cultura historiográfica brasileira sofria do "mal de Sísifo" de sempre voltar às origens (PIAZZA, op.cit., p. 18), fosse entre os membros do Instituto ou para os autores da moderna historiografia brasileira.

Em pesquisa recente sobre a história da historiografia no Brasil das décadas de 1940 a 60, Rebeca Gontijo e Fábio Franzini problematizam a memória que formou esse ideal moderno. Para os autores, o surgimento de publicações e pesquisas no âmbito dos programas de Pós-Graduação em todo o Brasil - com recortes temporais que datam da primeira metade do século XX e referentes aos chamados "autores do segundo time", como Manuel, Bonfim, Afonso Arinos, Otávio Tarquínio, por exemplo - ajudam na reavaliação de certos cânones (FRANZINI; GONTIJO, 2009).

Nesse movimento, o famoso prefácio de Antonio Cândido à quinta edição de Raízes do Brasil, escrito em 1967, é tomado como marco inaugural de uma nova visão a respeito dos intérpretes do Brasil, na qual a tríade Raízes do Brasil (1936), Casa Grande \& Senzala (1933) e Formação do Brasil Contemporâneo (1942) assume lugar de destaque. Ali, a memória produzida tem como marco o "fato" Revolução de 30. Para Antonio Cândido, "são esses os livros que podemos considerar chaves, os que parecem exprimir a mentalidade ligada ao sopro de radicalismo intelectual e análise social que eclodiu depois da Revolução de 1930 e não foi, apesar de tudo, abafada pelo Estado Novo" (Idem, p. 156).

De testemunho de uma geração que sofreu os impactos desses autores durante a formação secundária e universitária, o prefácio de Antonio Cândido, que se tornou independente de Raízes do Brasil, foi apropriado em muitos casos de maneira acrítica, e o que "nele era memória se cristalizou em história, do que decorreu uma canonização, ainda que informal, daqueles livros que supostamente haviam marcado a sua geração, ou ao menos, do qual o autor fazia parte" (Ibidem, p. 157) ${ }^{\mathrm{vii}}$.

Tais apropriações, que também se revelam no âmbito acadêmico, demarcaram o que se costumou chamar de "lugar-comum" quando a historiografia anterior a 1930 era vista de maneira homogênea, um conjunto monolítico marcado por leituras ditas oficiais, autorizadas, positivistas sobre o passado nacional, advindas de tradição criada pela fundação do IHGB em 1838 até 1930, momento de ruptura, de modo a permitir um (re)descobrimento do Brasil moderno, exemplificado pelos variados diagnósticos produzidos sobre o País. Por outro lado, o mesmo "lugar-comum" coloca a tríade interpretativa como o marco historiográfico posterior 
a 30, com seus frutos em gravitação, de forma direta ou indireta, em torno dela (Ibidem, p. 157-159).

A escrita de uma história oficial dentro de uma tradição de civilização e progresso se constituía como um dos objetivos do IHGB. Além desse, o Instituto previa a coleta e a publicação de documentos relevantes para a história do Brasil. Não obstante, observam-se similitudes entre um projeto proposto no século XIX e o projeto encabeçado pelos modernistas a partir da Coleção Biblioteca Histórica Brasileira.

Respaldados nos princípios da moderna historiografia, segundo os quais as fontes primárias desempenhariam para o trabalho do historiador um papel central, os integrantes do IHGB discutiam os meios de localização de documentos imprescindíveis à história do Brasil. De acordo com Manuel Salgado Guimarães, "a preocupação com o trabalho de localização de fontes no Brasil e no exterior acompanhou desde seu início o percurso do IHGB" (GUIMARÃES, op.cit., p. 19). Assim, foi constante por parte do órgão o incentivo a viagens e excursões para fora (em especial Portugal e Espanha) ou pelo interior do Brasil, na expectativa de que fossem coletados materiais que subsidiassem a escrita da história nacional (Idem).

É importante ressaltar que o advento da moderna historiografia no século XIX europeu está intimamente ligado a uma série de fatores conjunturais, dentre eles: o avanço da ciência moderna e da industrialização, com suas consequências nefastas; os processos de afirmação da identidade nacional, em especial na Alemanha e na França; a desvinculação da história dos campos filosófico e literário; o desenvolvimento de um método científico disciplinar, com base no empirismo ditado pela análise consistente das fontes documentais escritas e oficiais; do surgimento de diversas instituições e revistas de divulgação científica e da consequente profissionalização dos historiadores; e, por fim, a necessidade traduzida em ações de divulgação e cariz pedagógico (ensino primário, secundário e universitário) ou ainda em ritualizações comemorativas.

Desse modo, guiando-se pelo moderno fazer historiográfico num momento de definição da história pátria brasileira, as páginas trimestrais da revista do IHGB tornaram-se local privilegiado de divulgação das pesquisas até então feitas no Brasil. Num levantamento realizado junto às edições do periódico, Manuel Salgado constatou que três temas frequentemente davam o ar da graça: a problemática indígena; as viagens e explorações científicas; e o debate da história regional (GUIMARÃES, op.cit., p. 20). 
Na produção historiográfica das primeiras décadas do século XX é possível observar certa continuidade das temáticas oitocentistas que alimentaram o projeto de história do IHGB $^{\text {viii }}$. Buscava-se um diagnóstico para a nação, em especial nos embates modernistas sobre tradição e modernidade, publicava-se por meio de projetos editoriais, relatos e diários de expedições de viajantes europeus, como o fizeram os diretores da Biblioteca Histórica Brasileira, além de haver um empenho na busca por novas fontes que dissessem respeito ao Brasil. Nesse sentido, as correspondências trocadas entre Rubens Borba de Moraes e Sérgio Buarque podem ser reveladoras de pequenos fragmentos que apontam na direção de uma similitude de temáticas historiográficas.

Em carta de 24 de janeiro de 1940, Moraes respondia ao amigo: "Sérgio, recebi sua carta hoje. Vamos por partes". Em uma delas questiona o interlocutor sobre certa documentação histórica a ser trazida da França para o Brasil: “Quanto ao manuscrito existente na Sainte-Geneviève, em Paris, não ha dúvida que convém mandar copiar. Convem tirar copia fotográfica e traduzir aqui. Escreva ao seu cunhado nesse sentido. É preciso, em primeiro lugar, saber o tamanho do manuscrito, preço da copia, etc para depois a gente providenciar o mesmo" ix.

Meses depois este pedido é atendido por José Augusto, cunhado de Buarque, que se encontrava em Paris e que, da sala da "secção de manuscritos da Bibliothéque de St. Geneviéve", no dia 6 de abril redigia uma resposta ao parente. Na carta, além das intimidades familiares descritas mencionava a existência de documentos que interessavam ao historiador, dentre os quais, os manuscritos do viajante J. B. Douville, registrados de maneira bastante apurada:

Imagine que apenas 20 ou 30 manuscritos, dos milhares que eles são, restam na Bibliothéque de St. Geneviéve. Os outros foram se esconder "quelque part en province". Pois bem, entre os 20 ou 30 que ficaram, encontram-se o seu Douville. Consta de 137 folhas, das quaes 114 escritas no verso, (...) a escritura está nítida e não terei maiores dificuldades em decifrá-la. Cada pagina consta de uma média de 37 linhas e cada linha tem a media de 12 palavras. (...) As primeiras linhas em que o autor explica a briga que teve com o consul do Brasil em Portugal, devido a este ter se negado a visar seu passaporte para a Baía, enquanto não lhe fosse apresentada caução provando que Douville não era mendigo, vale um poema. (...) Percebi também que o livro tem explicações longas de medicina e das drogas indígenas e transcreve muitas cartas escritas e recebidas pelo outro no Brasil, de figuras de projeção nacionais e da França da época. O livro já começa no capítulo 3 mas ele é que interessa pois tem o unico nos preparativos de viagem da Europa para a 
América do Sul. As viagens do narrador são pela Baia, adjacencias de Ilheus até nascentes do rio Itahipe. ${ }^{\mathrm{x}}$

As observações de Borba revelam a importância fundamental que esses manuscritos tinham para a constituição da uma narrativa histórica nacional. Note-se ainda que a barreira da língua não constituía empecilho para esses homens de letras, e a "facilidade" em decifrar as informações contidas nas 137 folhas do documento trariam informações valiosas sobre a expedição do viajante francês pela América do Sul e pelo Brasil, em especial sobre os usos da medicina indígena e as descrições geográficas de rios da região da província da Bahia e adjacências, temas tratados por Buarque em trabalhos posteriores, como Monções e Caminhos e Fronteiras ${ }^{\mathrm{xi}}$.

Em outra missiva enviada por José Augusto a Buarque, o tema das fontes é novamente mencionado. Desta vez a resposta vinha de Lisboa, em 16 de outubro de 1940. A carta dá indicações claras de que os pedidos feitos do Brasil eram, em geral, atendidos:

Meu caro Cunhado e Professor, Estive hoje no Arquivo Colonial com o Dr
Múrias que é um desses portugueses que até parecem brasileiros - é delicado,
agradavel, interessantissio no bate papo. Elogiou o seu livro, fala muito no
Dr Afranio Peixoto, no Taunay, no Rodolpho Garcia etc... Colocou logo
todo o arquivo à minha disposição. Há lá coisas de $1^{\text {a }}$ ordem e inéditos.
Quasi todos os papeis referentes à história colonial nos seculos XVI, XVII e
XVIII (...) Quando eu cheguei o Dr Múrias estava justamente examinando o
processo de fundação do Convento N. S. da Ajuda, no Rio de Janeiro e
verificando que quem o fundou foi a mulher de um Bezerra de Menezes que
foi governador no Rio (...)Ando tambem atraz do seu capitão Lorena. Logo
que encontre as memórias desse malandro, escreverei a respeito para você
(...) Saudades a toda família e um abraço do José Augusto. xii

Os exemplos acima demonstram que, além dos relatos que interessavam para as futuras publicações da Coleção, outros tipos de fontes sobre o Brasil mereciam atenção especial. Interessavam os manuscritos, "papéis referentes a história colonial nos séculos XVI ao XVIII, o processo de fundação de um convento no Rio de Janeiro, livros de memória”. Entretanto, o que mudava era a forma de adquiri-las. Em vez de expedições financiadas pelo Estado, como no caso do IHGB, o que predominava era uma rede de relações pessoais e intelectuais em torno de um objetivo comum: a prática historiográfica. Fosse de Paris ou de Lisboa, o que importava nesse momento era trazer ao Brasil tudo o que lhe dissesse respeito. 
Nesse sentido, a publicação de Memórias de um colono no Brasil é emblemática, pois na apresentação da obra afirmava seu diretor: "pedimos a Sérgio Buarque que o traduzisse, prefaciasse e anotasse e, êle, com verdadeira consciência de historiador, descobriu os documentos inéditos que publicamos em apêndice e que são do mais alto interesse para o histórico da famosa revolta dos colonos de Ibicaba” (MORAES, 1941, p. 3).

Aqui, uma observação. Como não havia no Brasil do início do século XX distinções disciplinares mais nítidas até a institucionalização da disciplina histórica nas universidades brasileiras, eram considerados historiadores, em geral, os intelectuais que produzissem na área dos estudos históricos, e havia um esforço de distinção tanto da filosofia e da literatura quanto dos chamados estudos político-sociais. Desse modo, desde os tempos do IHGB os historiadores podiam ser também advogados, poetas, jornalistas, críticos literários ou desempenhar qualquer atividade que os ligasse ao ofício das letras. Consequentemente, sua consciência ligava-se aos paradigmas do moderno fazer historiográfico, cuja documentação (se inédita, melhor) constituía a matéria-prima principal das narrativas, independentemente de onde eram produzidas ou publicadas (GOMES, 1996).

Seguindo as cartas, ao considerarmos a trajetória de Yan de Almeida Prado, tudo leva a crer que foi em uma de suas viagens à Europa que o escritor, também colecionador de obras raras, tenha adquirido o original de Thomas Davatz que, em seguida, circulou entre os amigos modernistas. É o que demonstra a carta de Rubens Borba, enviada de São Paulo como resposta a Sérgio Buarque de Holanda, no dia 8 de dezembro de 1939. Dentre os assuntos tratados, o remetente informava que Ribeiro Couto lhe escreveria em breve para, em seguida, informar seu novo projeto editorial:

Dei os recados ao Couto. Ele escreverá a V. Vou amanhã falar com o Yan para ver se ele me empresta o Davatz para te mandar. Leia e mande me dizer se vale a pena $\mathrm{V}$. traduzir e prefaciar. O 1 número da minha collecção está no prelo e sahe com um atraso de 10 dias. Mas no dia 20 ou 26 está na rua. Em janeiro sahe o St. Hilaire. Se V. pudesse me aprontar o Davatz para fevereiro seria o ideal. É curtinho e facil. ${ }^{\text {xiii }}$

O empréstimo de livros e as leituras coletivas de obras literárias e históricas faziam parte, havia muito tempo, desse universo de seletos letrados partícipes da Semana de 22. Em um depoimento nos idos de 1982, Rubens Borba relembra bem esses fatos. Uma de suas explicações para essa circulação literária diz respeito a sua educação europeia, daí a necessidade e ele e outros amigos educados no estrangeiro quererem conhecer melhor a 
cultura brasileira, se "atualizarem". Partiram então para a leitura de autores nacionais, como José de Alencar, Afonso de Taunay, Varnhagen, Simão de Vasconcelos, Rocha Pita, entre outros. O importante aqui é que a ideia de "atualização" estava diretamente ligada a outra, de "releitura" da história do Brasil, mais moderna, portanto, de influência europeia, sem fatos, sem grandes pessoas, pela qual também se deveria voltar às fontes. Nos dizeres do bibliófilo aprendiz:

Agora, o que aconteceu comigo, aconteceu com os outros também. Aconteceu com o Mário, com o Oswald e com o Sérgio Milliet. Eu cheguei aqui sem conhecer a cultura brasileira porque tinha ido para a Europa com 9 anos; voltei com 20. De maneira que eu não conhecia a cultura brasileira. Comecei a ler. Passei três meses na fazenda com um monte de livros da biblioteca da fazenda. Os livros que havia na fazenda eram ruins. Tinha muito José de Alencar, tinha Taunay, tinha aqueles autores que meu avô e meu pai liam e gostavam. De maneira que eu me atualizei. Depois, como eu tinha uma inclinação por história, fui estudar história. Eu já via história a partir de umas teorias mais modernas, que eu tinha aprendido na Universidade de Paris. Já não era uma história de fatos, das grandes pessoas e tal. Falei: -"Mas está tudo errado! está tudo errado! Precisa-se estudar o Brasil. (...) Precisamos voltar às fontes, precisamos estudar as fontes para ver como é que se evoluiu (GOMES, 1982, p. 99).

Nesse contexto, o livro do colono suíço interessava aos organizadores da Biblioteca muito mais por seu valor documental sobre um tema pouco explorado pela historiografia do que por seu conteúdo literário. Ao prever que o título seria o quinto volume da coleção, Moraes deixou clara a importância do texto, que julgava uma preciosa fonte para o estudo da colonização em São Paulo.

A tradução do volume, de fato, realizou-se pelas mãos de Sérgio Buarque de Holanda que, à época, chefiava a seção de publicações do Instituto Nacional do Livro (INL), posição ocupada a convite de outro amigo em comum, o poeta gaúcho Augusto Meyer (1902-1970). O poeta e ensaísta nascido em Porto Alegre participou de uma intensa atividade intelectual. Em sua trajetória, colaborou com poemas e ensaios críticos em diversos jornais do Rio Grande do Sul, especialmente Diário de Notícias e Correio do Povo. Estreou na literatura em 1920 com o volume de poesias intitulado A ilusão querida, e com os livros Coração verde, Giraluz e Poemas de Bilu conquistou renome nacional. Estas e outras obras posteriores foram reunidas em Poesias (1957). Pseudônimo: Guido Leal. 
Em 1926 Augusto Meyer fundou com Teodomiro Tostes, Azevedo Cavalcante, João Santana e Miranda Neto a revista Madrugada. Foi diretor da Biblioteca Pública do Estado do Rio Grande do Sul, de 1930 a 1936. Em seguida parte para o Rio de Janeiro com outros intelectuais gaúchos trazidos por Getúlio Vargas, e eles organizam o Instituto Nacional do Livro, em 1937. Dentre as atribuições do novo órgão estavam a edição de obras literárias julgadas de interesse para a formação cultural da população, a elaboração de uma enciclopédia e de um dicionário nacionais, e a expansão de bibliotecas públicas por todo o território brasileiro (XAVIER, 2008, p. 27).

A composição de cargos aqui estabelecida por meio de afinidades eletivas vai ao encontro do que já foi exposto anteriormente sobre a "constelação Capanema". Desse modo, sob o governo Vargas, Buarque trabalhou, por intermédio de suas redes de sociabilidade, em Instituições vinculadas ao Ministério da Educação e Saúde Pública, primeiro como professor da extinta Faculdade do Distrito Federal, em 1936, e em seguida, entre 1937 e 44, no Instituto Nacional do Livro.

Dentro do que foi exposto até o momento, cabe um rápido questionamento: por que o livro de Davatz e o prefácio de Buarque se tornaram marco nos estudos sobre a colonização paulista no século XIX, a ponto de a obra ser elevada a tema nacional?

Ao convidar Buarque a elaborar o prefácio, Moraes assinalava sua paixão pelo tema da colonização paulista e sugeria ao historiador que o aprofundasse:

Se você acha que seria útil fazer um prefácio-estudo sobre a questão eu te peço que faça. O que você acha? Seria talvez melhor. Eu sou tão apaixonado por essa questão do estudo da colonização, tenho estudado tanto esse problema que gostaria até de escrever um livro sobre o assunto. Mas eu tenho preguiça de escrever livros. Prefiro fazer livros. É mais divertido. Mas você porque não escreve esse livro? Vamos, avante! Faça um prefácio para o Davatz com as diretrizes do futuro livro. ${ }^{\text {xiv }}$

Para a historiadora Ilka Cohen, estudiosa da imigração germânica no século XIX, o prefácio de Holanda se tornou um marco na historiografia sobre a colonização paulista. Ali se desenvolveu pela primeira vez, segundo ela, uma análise aprofundada da experiência da parceria, baseada no relato e nas memórias do colono Thomas Davatz. Desse modo, foi como um documento sobre a colonização de São Paulo que esse depoimento se consagrou. Ao texto original, completo, Sérgio Buarque acrescentou um conjunto de fontes sobre o levante dos colonos, além de extensa bibliografia que se tornou base para uma série de outras pesquisas 
sobre a temática da emigração e do trabalho livre em São Paulo no século XIX, e a questão da parceria emancipou-se com o tema. Ao que parece, mesmo sem intenção "o brilho do prefaciador ofuscou o prefaciado" (COHEN, op.cit., p. 184-185).

A apresentação de Moraes à primeira edição da obra oferece informações bastante relevantes. Para ele, o livro não é imparcial, é - antes - o libelo acusatório de um colono contra o patrão, "é o único depoimento existente escrito pela parte mais interessada: o colono", posição que fazia par ao coro de anos atrás iniciado por Mário de Andrade em suas crônicas no Diário Nacional. Em seguida, ele se refere novamente à importância do texto como documento histórico: "Não é somente a narração dramática da revolta desses pobres imigrantes contra um fazendeiro poderoso e respeitado que nos interessa como documento humano, mas, sobretudo, o estudo das condições de trabalho na fazenda como documento de história econômico-social" (MORAES, 1941, p. 3).

De volta à observação das cartas, é válido ressaltar as redes de amizade que cercavam os dois intelectuais envolvidos no processo de publicação dos escritos de Davatz. Não é demais lembrar que as correspondências comportam a troca de ideias, a elaboração de projetos, selam pactos, expõem polêmicas. Nesse pequeno mundo também se estabelecem uma geografia dos lugares ocupados pelos participantes e o afeto entre eles, as rivalidades, os conchavos estabelecidos em torno de ideias, obras, cargos e posições, inclusive as institucionais (MALATIAN, op.cit., p. 209). Comum entre os correspondentes eram também os pedidos de favores, as cobranças de prazos, o envio de lembranças aos amigos que estavam longe. Não obstante, aparecem nas cartas referências íntimas a escritores, professores universitários e a tantos outros intelectuais que ocupavam cargos importantes nas esferas do Estado Novo, em instituições de ensino e de cultura.

Aqui, alguns exemplos são reveladores dessas questões. Do conjunto epistolar pesquisado para este artigo, não raro foram as reclamações em tom de ironia que Rubens Borba fazia sobre a pessoa de Rodolpho Garcia. Em 18 de dezembro de 1939, o bibliófilo comentava com Sérgio Buarque de Holanda a falta de comprometimento do diretor da Biblioteca Nacional:

Não me admira que o Rodolpho Garcia nunca tenha feito uma permuta desde que é director. É bem da mentalidade desses velhinhos sabios, egoístas nocivos. Elle é um grande erudito mas de bibliothecas nada intende e não quer entender. Enquanto ele fica estudando no seu gabinete poeirento os 
bichos acabam com a Nacional. Qual esse Rio de janeiro não tem remedio...

No ano seguinte, em 18 de maio, Borba, com alto grau de intimidade perante o amigo paulista, pedia um pequeno favor, para em seguida revelar em tom descontraído sua aflição frente aos afazeres e ao calor da capital do País: "Vê se V. me cutuca o Meyer e o Aff. Arinos para tocarem as traduções. Eu ando meio aflicto e com medo que elles não me acabem isto tão cedo. No Rio não se trabalha e o paulista se aflige" xvi. Mais à frente, em 7 de novembro, escrevia novamente para Sérgio no mesmo tom: "Eu recebi uma carta do José Honório; como ando tonto de serviço só poderei responder mais tarde, mas diga a elle que estou de acordo com o preço do Nieuhof e o resto. Espero poder mandar a elle a tradução em breve pra elle rever, annotar (...) antes de ir para o prelo". xvii

No conjunto das cartas analisadas para este artigo foi possível perceber também a preocupação do remetente em relação aos outros livros que integravam a coleção. Em 24 de janeiro de 1940, Moraes escrevia: “Já vio o Rugendas? Os exemplares de luxo só ficam prontos no fim deste mês. Reservaremos um para V. Não sei o preço ainda. Porque V. não escreve um artigo em algum jornal sobre a coleção? Veja se me arranja aí um pouco de publicidade em torno da coleção. Bom, por hoje é só. Um abraço". xviii

Borba menciona também o lançamento da edição do Debret pelo amigo Martins, ao mesmo tempo que justificava novamente o atraso do lançamento do Davatz, que ficaria para o ano seguinte, o que de fato ocorreu:

Sérgio, recebi sua carta, o livro e as lembranças! Muito obrigado. Estamos aqui em grande actividade com o Debret que deve sahir sem falta até o fim do mez. O Martins vae fazer um lançamento á americana... Envestiu um capital enorme e agora não quer soltar mais livro nenhum tão cedo. Mas tudo depende da venda do Debret. Por causa desses negócios o Davatz vae ficar atrazado. Talvez não sahia este ano! Mau, mau... ${ }^{\text {xix }}$

Em outras correspondências, o suspense quanto ao lançamento ou não da tradução de Davatz é mais evidente, mesmo porque o livro já se encontrava praticamente pronto. Na sequência de epístolas iniciadas em agosto é possível acompanhar parte desse impasse. No dia 30, Borba lembrava ao amigo: "Sérgio, recebi sua carta. Não há dúvida: publique o seo prefácio no Davatz. Até é bom, faz propaganda do livro que por sinal não sahirá este anno". Já em 7 de novembro, novamente a esperança de que a obra sairia no ano então corrente foi 
renovada, haja vista "as provas já estarem prontas": “O Davatz está nas provas. Sahirá em dezembro na certa. Eu não creio necessário mandar as provas a V., não? Se achar que sim, avize" $^{x x}$.

Por fim, em $1^{\circ}$ de dezembro Borba cobrava certa urgência quanto à disposição das notas no livro feitas por Buarque, isso porque o volume já estava sendo impresso: "Quanto as suas notas do Davatz não sei se dará tempo. O volume está sendo impresso, já conseguimos as ultimas provas. Em todo o caso mande com urgência, indicando o lugar exacto que eu vou ver se dou um jeito. Mas mande com urgência" xxi .

O fim é conhecido, o livro sairia apenas no ano seguinte.

\section{Referências Bibliográficas}

ALTAMIRANO, C. Idéias para um programa de história intelectual. In: Tempo Social Revista de Sociologia da USP. São Paulo: USP, v.19, n. 1, jul.2007. p.9-17.

ANDRADE, M. de. Taxi e Crônicas no Diário Nacional; introdução e notas de Telê Ancona Lopez. São Paulo: Duas Cidades: Secretaria de Cultura, Ciência e Tecnologia, 1976.

BEIRED, J. L. B. Vertentes da História Intelectual. In: BARBOSA, C. A. S.; GARCIA,T. da C.(orgs). Cadernos de Seminário de Pesquisa: Cultura e Política nas Américas. Assis: UNESP, 2009. p. 86-98.

BOTTOMORE, T. Dicionário do pensamento marxista. Rio de Janeiro: Jorge Zahar, 2001. p. 194-195.

BREDIN, J. O caso Dreyfus. São Paulo: Scritta, 1995.

CARVALHO, J. M. de. História Intelectual no Brasil: a retórica como chave de leitura. In: Topoi: Revista de História do Programa de Pós-Graduação em História Social. Rio de Janeiro: UFRJ, n. 1, 2000. p. 123-152.

CATROGA, F. Memória e história. In: PESAVENTO, S. J. (org.). Fronteiras do milênio. Porto Alegre: Editora da UFRGS, 2001.

CHARTIER, R. História Intelectual e história das mentalidades: In: À beira da

falésia: a história entre certezas e inquietudes. Porto Alegre: Editora da UFRGS, 2002. p. 23-60.

COHEN, I. S. Thomas Davatz revisitado: reflexões sobre a imigração germânica no século XIX. In: Revista de História. n. 144, 2001. 
DECCA, E. S. de. O silêncio dos vencidos: memória, história e revolução. 6.ed. São Paulo: Brasiliense, 1994.

DOSSE, F. Biografia Intelectual. In: O desafio biográfico: escrever uma vida. São Paulo: EDUSP, 2009. p. 361-403.

FRANZINI, F. ̀̀ sombra das palmeiras: a coleção Documentos Brasileiros e as transformações da historiografia nacinal (1936-1959). 2006. Tese (Doutorado em História Social). Faculdade de Filosofia, Ciências Humanas e Letras, USP, São Paulo, 2006.

; GONTIJO, R. Memória e história da historiografia no Brasil: a invenção de uma moderna tradição, anos 1940-1960. In: SOHIET, R. (et al. ) Mitos, projetos e práticas políticas: memória e historiografia. Rio de Janeiro: Civilização Brasileira, 2009.

FREYRE, G. Prefácio. In: HOLANDA, Sérgio Buarque. Raízes do Brasil. Rio de Janeiro: José Olympio, 1936.

GAY, P. Modernismo: o fascínio da heresia. De Baudelaire a Beckett e mais um pouco. trad. Denise Bottmam. São Paulo: Companhia das Letras, 2009.

GOMES, Â. de C. Escrita de si, escrita da história: a título de prólogo. In: . (Org). Escrita de si, escrita da história. Rio de Janeiro: Ed. FGV, 2004. 1996.

História e Historiadores: a política cultural do Estado Novo. Editora FGV,

GONÇALVES, L. R. Sérgio Milliet, crítico de arte. São Paulo: Perspectiva: Edups, 1992.

GRANJON, M. Une enquête compare sur l'histoire des Intellectuels: sunthèse et perspectives. In: TREBITSCH, M.; GRANJON, M. (Direc). Pour une histoire compare des intellectuels. Paris: Editions Complexe; IHTP/CNRS, 1998. p. 19-36.

GUIMARÃES, M. L. S. Nação e civilização nos trópicos: o Instituto Histórico e Geográfico Brasileiro e o projeto de uma história nacional. In: Estudos Históricos. n. 1. Rio de Janeiro, 1988.

Entre as Luzes e o Romantismo: as tensões da escrita da história no Brasil oitocentista. In: ___ (org). Estudos sobre a escrita da história. Rio de Janeiro: 7 Letras, 2006.

HALLEWELL, L. O livro no Brasil: sua história. 2. ed. EdUSP, 2005. p. 502.

MALATIAN, T. Narrador, registro e arquivo. In: PINKY, Karla Bessanezi; LUCA, Tânia Regina de. O historiador e suas fontes. São Paulo: Contexto, 2009.

MALERBA, J. (org.). Lições de história: o caminho da ciência no longo século XX. Rio de Janeiro: Editora FGV, 2010. 
MORAES, M.A.de. Edição da correspondência reunida de Mário de Andrade: histórico e alguns pressupostos. In: Patrimônio e Memória. UNESP-FCLAs- CEDAP, v.4, n.2, p. 114- jun.2009.

MORAES, R. B. de. Apresentação. In: DAVATZ, Thomas. Memórias de um colono no Brasil. São Paulo: Livraria Martins Editora, 1941.

ORTIZ, R. Cultura brasileira e identidade nacional. 5. ed. São Paulo: Brasiliense, 1994.

PIAZZA, M. de F. F. Os Afrescos nos trópicos: Portinari e o mecenato Capanema. 2003. Tese (Doutorado em História Cultural) UFSC, Centro de Filosofia e Ciências Humanas, Florianópolis, 2003.

PONTES, H. Destinos Mistos: os críticos do grupo Clima em São Paulo (1940-1968). São Paulo: Cia. Das Letras, 1998.

VELloso, Monica Pimenta. História e Modernismo. Belo Horizonte: Autentica Editora, 2010.

XAVIER, L. R. Patrimônio em prosa e verso: a correspondência de Rodrigo Mello Franco de Andrade a Augusto Meyer. Mestrado Profissionalizante em Bens Culturais e Projetos Sociais. CPDOC, Fundação Getúlio Vargas, 2008.

\begin{abstract}
Notas

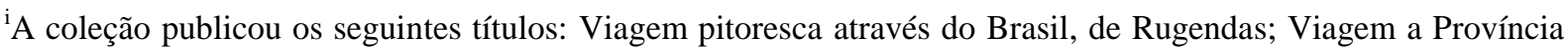
de São Paulo, de Auguste de Saint-Hilaire; Reminiscências de viagem, de Danil Kidder; Viagem pitoresca e histórica ao Brasil, de Jean-Baptiste Debret; Memórias de um colono no Brasil, de Thomas Davatz; Brasil Pitoresco de Charles Ribeyrolles; Viagem a terra do Brasil de Jean de Léry; Dez anos de Brasil de Carl Sedler; Memorável viagem marítima, de Joan Nieuhof; Notas sobre o Rio de Janeiro de John Luccock; Viagem as missões jesuíticas do Padre Antônio Sepp von Rechegg; Imagem do Brasil de Frans Post; Os caduveos de Guido Boggiani; História das missões dos padres capuchinos, de Calude D’Abbeville; Notícia do Brasil de Gabriel Soares de Souza; História da guerra Rio e Buenos Aires e Galeria dos Brasileiros Ilustres de S.A Sisson.

ii Para essa discussão utilizei como referências os seguintes textos: ALTAMIRANO, Carlos. Idéias para um programa de história intelectual. In: Tempo Social Revista de Sociologia da USP. São Paulo: USP, v.19, n. 1, jul.2007. p.9-17; BEIRED, José Luis Bendicho. Vertentes da História Intelectual. In: BARBOSA, Carlos Alberto Sampaio; GARCIA,Tânia da Costa (orgs). Cadernos de Seminário de Pesquisa: Cultura e Política nas Américas. Assis: UNESP, 2009. p. 86-98; BOTTOMORE, Tom. Dicionário do pensamento marxista. Rio de Janeiro: Jorge Zahar, 2001. p. 194-195; CARVALHO, José Murilo de. História Intelectual no Brasil: a retórica como chave de leitura. In: Topoi: Revista de História do Programa de Pós-Graduação em História Social. Rio de Janeiro: UFRJ, n. 1, 2000. p. 123-152; CHARTIER, Roger. História Intelectual e história das mentalidades: In:___ À beira da falésia: a história entre certezas e inquietudes. Porto Alegre: Editora da UFRGS, 2002. p. 23-60; DOSSE, François. Biografia Intelectual. In: ___. O desafio biográfico: escrever uma vida. São Paulo: EDUSP, 2009. p. 361-403; GRANJON, Marie-Christine. Une enquête compare sur l'histoire des Intellectuels: sunthèse et perspectives. In: TREBITSCH, Michel; GRANJON, Marie-Christine (Direc). Pour une histoire compare des intellectuels. Paris: Editions Complexe; IHTP/CNRS, 1998. p. 19-36.

iii Sobre esse episódio, remeto à discussão proposta por Edgar de Decca. Para o autor, "a revolução de 30 como memória histórica do vencedor da luta, fazendo parte do exercício de dominação, edifica o futuro, ao mesmo tempo que refaz o passado, qualificando tanto os agentes como seu próprio sentido. Toda a história transcorrida até 30 é memorizada pelo vencedor como uma luta entre dois agentes sociais, os revolucionários e a oligarquia".
\end{abstract}


No que diz respeito à construção de uma memória histórica pelo vencedor, o autor também chama a atenção para a cronologia criada após esse "fato". Nesse sentido, tudo o que viria antes dele seria denominado "República Velha", já que "tal revolução inaugura o novo". A historiografia realizaria ainda sobre este "fato" outras polarizações, entre as quais a mais corrente é a da economia agroexportadora x industrialização, aspectos que marcaram profundamente a produção historiográfica ao longo do século XX. DECCA, Edgar S. de. O silêncio dos vencidos: memória, história e revolução. 6.ed. São Paulo: Brasiliense, 1994. págs. 108-110.

${ }^{\text {iv }}$ Vale ressaltar que a passagem aqui citada é apontada por Ilka Cohen como sendo do segundo artigo publicado por Mário de Andrade no dia 16 de agosto. Fica, portanto, o registro de que tal passagem é de fato do primeiro artigo.

${ }^{\vee}$ Vale ressaltar que Rubens Borba de Moraes e Sérgio Milliet eram amigos de longa data. Os dois estiveram na Suíça por volta de 1912 a 1920 e viveram uma vasta experiência cultural no meio artístico europeu da época, tornando-se mais tarde, devido a esta vivência, nomes fundamentais para a concretização do movimento modernista paulista do início dos anos 20. Para mais detalhes sobre a vida de Milliet, ver: GONÇALVES, Lisbeth Rebollo. Sérgio Milliet, crítico de arte. São Paulo: Perspectiva: Edups, 1992. p. 23.

${ }^{v i}$ Vele mencionar que pouco antes da criação do IHGB, em 1838, o Jornal O Patriota, editado no Brasil por Manuel Ferreira de Araújo Guimarães (1777-1938), já trazia em suas páginas metáfora semelhante. A analogia aqui era referente à vertigem política pela qual passava a corte em Lisboa, decorrente do terremoto e da invasão napoleônica. Desse modo, a América surgia como um local preservado de terremotos, inclusive os políticos, que abalavam a Europa, portanto, uma terra onde se poderia assegurar a continuidade do trono dos Bragança. Sobre essas discussões historiográficas no Brasil do século XIX, ver também: GUIMARÃES, Manuel Luiz Salgado. Entre as Luzes e o Romantismo: as tensões da escrita da história no Brasil oitocentista. In: sobre a escrita da história. Rio de Janeiro: 7 Letras, 2006. p. 73.

vii Colaborando com essa perspectiva, temos Renato Ortiz, quando analisa Ideologia da cultura brasileira, de Carlos Guilherme Mota. O autor referencia o prefácio de Antonio Candido no que se refere a uma mudança na historiografia brasileira a partir dos anos 1930. Ortiz questiona o fato de que ao se fazer essa operação "não estaríamos tomando o testemunho de um autor (Cândido) pela própria explicação histórica". Menciona ainda o fato de Sérgio Buarque e Caio Prado Jr. estarem nas origens da instituição universitária no Brasil (nesse caso, a USP, da qual Cândido fala) e tece rígidas críticas ao apontar que "Sérgio Buarque e Caio Prado Jr. significam rupturas não tanto pela qualidade do pensamento que produzem, mas sobretudo pelo espaço social que criam e que dá suporte às suas produções". ORTIZ, Renato. Cultura brasileira e identidade nacional. 5.ed. São Paulo: Brasiliense, 1994. p. 40.

viii $\mathrm{O}$ intuito do artigo é demonstrar semelhanças no que se refere à forma de obtenção documental, em especial nos arquivos europeus. Quanto à produção historiográfica na primeira metade do século XX, em especial aquela produzida fora das recém-criadas faculdades de filosofia do período, o já citado trabalho de Fábio Franzini demonstra a heterogeneidade dela, inclusive nas temáticas. A coleção Documentos Brasileiros, por exemplo, publicou ensaios interpretativos, memórias, relatos, biografias dentro de temáticas como política, ciência, literatura, sociedade, e história regional, numa contraposição à afirmação paulista de história nacional a partir da figura do Bandeirante. Por outro lado, a Documentos deixaria de lado a história de viés marxista, embora tenha publicado alguns títulos de Nelson Werneck Sodré, produzida entre outros autores por Caio Prado Júnior. Sobre essa temática ou política afirmativa de memória historiográfica ver, por exemplo, o livro de Ana Claudia Fonseca Brefe, O Museu Paulista: Affonso de Taunay e a memória nacional (1917-1945). Editora Unesp: Museu Paulista, 2005.

ix Carta de Rubens Borba de Moraes a Sérgio Buarque de Holanda, 24 de janeiro de 1940. Arquivo Central Unicamp. Nas próximas referências os nomes serão abreviados. Por opção minha, os trechos citados permanecerão conforme aparecem nas cartas.

${ }^{x}$ Carta de RBM a SBH, 6 de abril de 1940.

${ }^{x i} J e a n$ Baptiste Douville (1794-1837) além de ter feito expedições pela África e pela Índia, esteve em outras partes da América do Sul e no Brasil por volta de 1826 e 1827. Sua morte no rio São Francisco em 1837 é narrada pelo doutor G. Gardner no livro Travels in the Interior of Brazil publicado em 1846.

xii Carta de José Augusto a Sérgio Buarque de Holanda, 16 de outubro de 1940. Possivelmente trata-se de Manuel Múrias (1900-1960), um dos mais significativos nomes da segunda geração do Integralismo Lusitano, que abraçou, ainda estudante, na Faculdade de Letras de Lisboa (curso de Filologia Românica). Destacou-se como publicista, enquanto diretor da Nação Portuguesa (cargo em que sucede a António Sardinha) e nos jornais A Voz e Época. Dirigiu posteriormente vários órgãos ligados ao movimento monárquico e ao Estado Novo, como a Revolução Nacional, o Diário da Manhã e o semanário Acção. Foi director do Arquivo Ultramarino e deputado na Assembleia Nacional. Como historiador, dedicou-se especialmente ao período de ouro dos séculos 
XV a XVII e ao tema da expansão ultramarina. Sua grande obra neste campo é "História da Expansão Portuguesa no Mundo" (3 volumes). Foi um dos que mais contribuíram para afirmar a visão da "História da Expansão" ligada ao Estado Novo, com as suas obras escritas em estilo popular, divulgadoras mais que inovadoras, fortemente patrióticas e nacionalistas. (in: Dicionário Cronológico de Autores Portugueses, Vol. IV, Lisboa, 1997. Acessado no site: http://forumpatria.com/cultura-e-patrimonio-portugues/manuel-murias/ em 01 de março de 2011 às 15 h51 min. O livro em questão é "Raízes do Brasil", publicado em 1936, que abriu a coleção Documentos Brasileiros da editora José Olympio, dirigida no início por Gilberto Freyre e mais tarde por Otávio Tarquínio de Souza. Imagino que seja o mesmo Lorena descrito no capítulo XXIII do livro "História de São Paulo”, de Afonso D’Escrognale Taunay como Bernardo José de Lorena, que assumiu o governo de São Paulo a 15 de julho de 1788, substituindo Gama Lobo. Segundo o autor, "o rapazola de verdes anos" governou durante nove anos. p. 193.

xiii Carta de Rubens Borba de Moraes a Sérgio Buarque de Holanda. 8 de dezembro de 1939.

${ }^{\text {xiv }}$ Carta de RBM a SBH, 18 de maio de 1940.

${ }^{x v}$ Carta de RBM a SBH, 18 de dezembro de 1939.

xvi Carta de RBM a SBH, 18, de maio de 1940.

xvii Carta de RBM a SBH, 7 de novembro de 1940.

xviii Idem.

${ }^{\text {xix }}$ Carta de RBM a SBH, 14 de ? de 1940. É bem possível que a carta tenha sido escrita no final do ano mencionado. No próprio catálogo do Arquivo Sérgio Buarque de Holanda ela se encontra sem a especificação do mês, mas em sequência às demais citadas neste artigo.

${ }^{\mathrm{xx}}$ Carta de RBM a SBH, 7 de novembro de 1940.

${ }^{x x i}$ Carta de RBM a SBH, 1 de dezembro de 1940.

Recebido em agosto/2012.

Aprovado em setembro/2012. 